\title{
Health economics: implications for novel antirheumatic therapies
}

\section{A Kavanaugh}

This paper discusses the pharmacoeconomics issues relating to the use of the newer therapies for rheumatoid arthritis (RA), namely the tumour necrosis factor (TNF) inhibitors. Results of recent studies have provided some evidence regarding the cost effectiveness of these agents. However, as the use of TNF inhibitors evolves-including their use in other systemic inflammatory diseases - this will be influenced by several factors including treatment of patients with early RA, longer term treatment, problems related to toxicity, quality of life, productivity, and market forces. Thus, pharmacoeconomic considerations are likely to remain a central factor in the use of novel therapies in rheumatology, and awareness about these will aid clinicians to select the most favourable therapies for their patients with arthritis.

$\mathrm{R}$ heumatoid arthritis (RA) is a chronic autoimmune condition that exacts a considerable toll from affected patients. ${ }^{1}$ The joint destruction and progressive functional disability characteristic of uncontrolled RA are associated with substantial economic costs not only to the patients and their families, but also to society. In recent years, significant progress in understanding the immunopathogenesis of RA combined with advances in biotechnology has led to the development of agents that therapeutically target specific components of the dysregulated immune system. Such "biological agents", particularly the inhibitors of the key proinflammatory cytokine tumour necrosis factor $\alpha$ $(\mathrm{TNF} \alpha)$, have proved highly effective not only in improving the signs and symptoms of disease, but also in attenuating the progression of joint damage, improving quality of life, and preserving functional status. ${ }^{2-10}$ The introduction of TNF inhibitors has engendered a dramatic change in the therapeutic approach for RA. ${ }^{11}$ Thus, the ability to improve clinical outcomes in such a meaningful way has resulted in the goals of treatment being raised. Remission is now considered not only highly desirable, but also an appropriate goal for treating RA patients. In addition, biological agents have been shown to have impressive utility in systemic inflammatory diseases other than RA, including psoriatic arthritis, ankylosing spondylitis, psoriasis, and inflammatory bowel disease.

A worldwide concern that has impacted on the clinical use of biological agents is their relatively high acquisition costs. ${ }^{12}$ In the USA, the May 2005 average wholesale price (AWP) for one year of therapy with standard RA dosages of either etanercept or adalimumab was approximately US\$15 680; the cost of infliximab is comparable (US\$10 450-18 110, for two vials/treatment on maintenance schedule to three vials/ treatment including an initiation regimen; exclusive of administration costs). Although costs slightly lower than AWP may be available by discounting and other means, the costs of the three currently available TNF inhibitors still far exceed those of older therapeutic agents. The AWP for one year of treatment with generic methotrexate at a dose of $17.5 \mathrm{mg} /$ week is approximately US\$500. With healthcare costs rising globally, and with newer therapeutics consuming a greater portion of healthcare budgets, there has been increased attention towards pharmacoeconomic analyses as a means to justify therapy with these newer, more expensive agents. ${ }^{12-22}$ Although health economic assessments are thus critically important, characteristics of such analyses can make them seem imprecise. For example, there can be substantial heterogeneity in the methods employed, the perspective chosen, the outcomes assessed, and the timeframes used, among other factors. In rheumatology, there has been both substantial interest as well as strong debate about the most appropriate methods for pharmacoeconomic assessment of rheumatic diseases. ${ }^{12-20}$ A point upon which there is agreement is that pharmacoeconomic considerations should be an integral part of the decision to use biological therapies.

\section{PHARMACOECONOMIC ANALYSES}

Various methods of health economic analyses can be used. Cost identification analyses simply measure particular components, such as the cost of a new therapy, or the cost of hospitalisations. This simple approach does not include valuation of efficacy. Cost benefit analyses express all components and outcomes in monetary terms. As outcomes are implicitly comparable, such analyses allow some economic comparison of different strategies. Cost effectiveness analyses have become the standard method for attempting to measure the value of newer therapies. In this type of assessment, the clinical benefit of the newer treatment is compared with a standard therapy, as are the costs. The metric used can be any relevant clinical outcome, such as number of deaths or $1 \mathrm{~kg}$ change in weight. However, cost per quality adjusted life year (QALY), sometimes referred to as a cost utility analysis, has become widely used. Cost per QALY, particularly if the analysis is conducted over a sufficiently long time line, has the advantage of allowing comprehensive assessment of the impact of a treatment. Such analyses also allow comparisons among disparate medical conditions and their treatment. For example, the cost per QALY for chemotherapeutic treatment of a type of cancer can be compared with the cost per QALY of surgical treatment of a damaged blood vessel.

Central to any pharmacoeconomic analysis is a comprehensive collection of costs related to the disease being assessed (box 1). Total costs are commonly subdivided into direct costs, indirect costs, and intangible costs. The direct costs of a disease should include all healthcare resources related to the disease, including costs for all related office visits and hospitalisations, and also the medications used. Although seemingly straightforward, different studies can arrive at distinct results for such costs, depending on how the assessment was performed. In RA, hospitalisations for orthopaedic surgery are quite expensive. This is a key 
Box 1: Pharmacoeconomic analyses in rheumatoid arthritis (RA): costs

Direct costs

- Medications (including administration costs)

- Hospitalisations (related to RA or its treatment)

- Orthopaedic surgery

- Extended care/rehabilitation facilities

- Outpatient surgeries

- Clinic visits

- Physicians

- Other healthcare providers (for example physiotherapists)

- Urgent care/emergency room

- Laboratory monitoring

- Imaging

- Toxicity (diagnosis, treatment)

- Medical assist devices

Indirect costs

- Productivity/opportunity costs

- Lost employment/wages

- Replacement household help

- Failure costs (direct and indirect costs for alternative treatment)

Intangible costs

- Quality of life

- Pain, depression/anxiety

consideration for highly effective therapies, as treatments that obviate the need for surgery in effect achieve a cost savings. However, orthopaedic surgery typically is not required until later in the disease course, and studies conducted over a short time frame might exclude this important item. Also, rates of orthopaedic surgery and other hospitalisations vary across regions. This highlights the need for time frames in economic analyses of RA that are sufficiently long to capture relevant outcomes, and well as the need for sensitivity analyses to capture variability in these outcomes. Other direct costs include clinic visits, physiotherapy, and costs associated with monitoring for and treating toxicities that arise as a result of therapy.

Indirect costs relate to the impact of the disease, such as the inability to work while afflicted. In conditions such as RA, indirect costs are extremely important. However, due to variability inherent in the methods used to collect them, as well as assumptions and extrapolations used to gauge their impact over time, indirect costs may appear less rigorous or exact, as compared with direct costs. The commonly used "human capital approach" considers the loss of productivity in work due to disease related disability and absenteeism from employment. The time missed from work due to the disease, multiplied by the affected person's salary yield the indirect cost of the disease. This method of assessment is relatively utilitarian in its viewpoint; it could be argued that the value of healthy humans cannot necessarily be entirely accounted for by their work productivity. Ethical considerations aside, there are other considerations that affect the interpretation of indirect costs. For example, distinct results may be obtained depending on the viewpoint chosen for the assessment. From the afflicted person's point of view, economic losses continue until the disease subsides and employment can be regained, or until social benefits replace income lost if the disease continues to prevent employment. From the employer's perspective, losses occur only until a replacement worker can carry out the duties of the afflicted, yielding a much smaller "friction cost". In addition, indirect costs may not obtain a full accounting of the impact of disease. For example, even if they do go to work, affected patients may have substantially reduced productivity related to their disease. This so-called "presenteeism" is not usually included in indirect cost assessments, and is relevant to patients with arthritis. Also, from the patient's perspective, arthritis can interfere with career advancement and concomitant increases in income that would otherwise have been expected had he or she not developed RA. Such costs, although important to patients and their families, are hard to quantify, and hence seldom accounted for. In addition to costs related to work outside the home, lack of productivity related to home care must also be assessed. This is of course relevant to the RA population, with a female preponderance and an age at onset that results in a fewer patients working outside the home than would be expected in a younger population with a greater proportion of men. Attempts have been made to value the indirect costs related to impaired ability to function within the home, for example by assessing the costs to hire outside help to perform tasks around the house.

Other costs that are relevant to a discussion of newer RA treatments are "failure costs" and intangible costs. Failure costs refer to those costs generated by therapies that a patient is currently taking, but that could be discontinued if a newer therapy were very effective. Thus, if a newer therapy allows discontinuation of other treatments for the same disease, then the direct and indirect costs related to those medications ought to be accounted for. In RA, use of the TNF inhibitors has been shown to allow reduction in the use of glucocorticosteroids and non-steroidal anti-inflammatory drugs (NSAIDs). Although the acquisition costs of these medications are relatively low, the treatment of adverse effects related to their use can be costly. For corticosteroids, this would include glucocorticoid induced osteoporosis and accelerated atherosclerosis, and potentially myriad other side effects. ${ }^{23}$ For NSAIDs, this would include any costs related to the diagnosis, treatment, and prevention of gastrointestinal bleeding related to the use of these medicines. Intangible costs, such as those related to pain and depression due to the impact of the disease, are seldom directly accounted for, as there is not a useful metric for doing so. However, measuring the impact of disease on functional status and overall wellbeing does allow the calculation of changes in QALYs related to the disease and to its treatment.

\section{THE COSTS OF RHEUMATOID ARTHRITIS}

Considering the basic principles of pharmacoeconomic analysis, the health economic argument related to the value of newer therapies for RA can be laid out in a relatively straightforward manner (box 2). A wealth of literature attests to the severity of RA, in terms of substantial morbidity and even accelerated mortality. ${ }^{24-27}$ Without effective treatment, the expected course of RA is one of progressive functional disability. ${ }^{28-35}$ Comprehensive studies from diverse countries have consistently shown progressive work disability among patients with RA. A recent systematic review of the literature showed a linear relation between disease duration and work 
Box 2: Health economic argument regarding new therapies for rheumatoid arthritis (RA)

- RA is a serious condition, associated with substantial morbidity and accelerated mortality

- The natural course of RA is one of progressive joint damage and disability

- RA is expensive, as affected persons have significant functional disability

- The costs of RA vary directly with the severity and activity of disease

- Newer therapies may be cost effective, depending upon their clinical benefit

disability. ${ }^{33}$ The related implication of functional disability is costs. Again, in the rheumatological literature there is a plethora of assessments clearly demonstrating that RA is a costly disease, and that the costs vary directly with functional disability..$^{21}{ }^{22}{ }^{36-45}$ Heterogeneity among the studies precludes meaningful averaging to yield a single dollar assessment. However, in a number of studies, total yearly costs per RA patient were approximately US\$10 000 (US 2005 dollars). It should be noted that there are studies in which costs were either lower or greater than this, attesting to heterogeneity of the assessments. The studies varied as regards geographical locale, the year in which they were conducted, characteristics of the RA populations included, the methods used to collect data, and other factors.

Despite some variation in absolute costs of RA noted among the studies, there are several consistent key themes across them. Indirect costs typically exceed direct costs, not infrequently by a factor of two. It should be noted that this was not true in all studies; also, with higher acquisition costs for medication, it would be expected that direct costs would increase. Importantly, in most of the studies, the costs of disease were not uniformly distributed among the RA population. This skewing, evidenced by the common finding that mean costs far exceed median costs, reflects the substantially higher costs incurred by a subset of the RA patients assessed. A key observation was that patients with the most severe RA incurred the highest costs. Relevant to pharmacoeconomic assessments of TNF inhibitors, patients with the most severe disease have been the type of RA patient for whom these agents have been most commonly used. The strongest predictor of cost was functional disability, typically measured with the Health Assessment Questionnaire (HAQ). Very consistently, elevated HAQ scores resulted in greater costs of RA. $.^{36} 39{ }^{41} 43-45$ In a recent rigorous analysis from Spain, there was an increment of more than US\$11 000 (US 2003 dollars) per unit of HAQ score among RA patients. Germane to pharmacoeconomic analysis, worsening in HAQ score over time resulted in higher costs whereas improvements resulted in lower costs of disease. The implication of this is that therapeutic agents capable of achieving significant improvements in functional status would be expected to lower the costs of disease. Improvement in functional status correlate with, and can also be used to quantify, improvements in quality of life, a key metric for cost assessments. ${ }^{12} 46$

\section{COST EFFICACY OF NEWER THERAPIES FOR RHEUMATOID ARTHRITIS}

In RA, there is a growing body of data addressing the potential cost effectiveness of TNF inhibitors. ${ }^{47-56}$ Even prior to the introduction of these agents to the clinic, cost assessments suggested that their relatively higher acquisition
Table 1 Cost effectiveness of tumour necrosis factor inhibitors ${ }^{12}$

\begin{tabular}{lll}
\hline Agent & Reference & $\begin{array}{l}\text { Cost per QALY } \\
\text { (US\$) }\end{array}$ \\
\hline Infliximab & Wong et $\left.a\right|^{47}$ & 30500 \\
Infliximab & Kobelt et $a$ A $^{48}$ & 34320 \\
Etanercept & Brennan et $a{ }^{50}$ & 29394 \\
Adalimumab & Bansback et $a$ F $^{53}$ & 28924 \\
\hline QALY, quality adjusted life year. & \\
\hline
\end{tabular}

costs would substantially affect their overall value. ${ }^{56}$ Nevertheless, because of their remarkable clinical efficacy in RA, it appears that TNF inhibitors may have an incremental cost within the range of generally accepted medical interventions. Much of these data comes from follow up of patients participating in clinical trials of infliximab, etanercept, and adalimumab in RA. In general, changes in health states, such as the HAQ score, are modelled over time using data from the studies. Simulations are performed using sensitivity analysis to account for reasonable variations in relevant outcomes. Either directly or indirectly-for example by transforming functional status-utilities can be created for the various transition states that then define the level of response to treatment in terms of QALYs gained. Cost effectiveness estimated can then be generated.

Remarkably, studies using distinct populations and agents have come to similar estimates (table 1). ${ }^{1247485053}$ Thus, treatment with a TNF inhibitor costs roughly US\$30 000 per discounted QALY gained. The costs are even lower if the base estimates are expanded to include savings in indirect costs. ${ }^{12}$ Several caveats are relevant to these types of study. ${ }^{19}{ }^{20}$ It has been argued that improvements in HAQ in research studies tend to be exaggerated and do not reflect efficacy achieved in clinical practice. The use of modelling, necessary to obtain data over a sufficiently long time frame, also has the potential to introduce inaccuracy. On the other hand, some factors make the estimates derived from clinical trials potentially conservative. For example, there are inherent differences in clinical trials as opposed to clinical practice, such as forced regular visits and the inability to capture "failure costs". Perhaps most importantly, these assessments used data from all of the treated patients. If the analysis was restricted to those patients achieving good or superior clinical outcomes, as would more closely approximate clinical practice, greater cost efficacy would be expected.

Despite potential imperfections in the analyses, the consistent demonstration that the cost per QALY for TNF inhibitors is approximately US\$30 000 is critically important. In general, largely for historical political reasons, interventions that achieve a cost per QALY gained of less than US\$50 000 are considered to be "cost effective". This benchmark is widely referenced and quoted for interventions in other disciplines. Thus, the issues surrounding the use of TNF inhibitors segue into political considerations, related to access and availability of agents for different disease states.

\section{CONCLUSION}

The relatively higher acquisition costs of novel biological agents has brought pharmacoeconomic considerations to the forefront in rheumatology. Fortunately, as regards RA, there are myriad data confirming the substantial cost implications of this pernicious disease. For the TNF inhibitors, the notable clinical efficacy observed needs to be factored into a comprehensive assessment of their value. Results from a number of studies have begun to make a compelling case that these agents may indeed be cost effective. 
As the use of TNF inhibitors evolves, additional health economic issues may also come into play. For example, when considering treatment of patients with early RA, a topic gaining wider discussion each year, distinct pharmacoeconomic issues might arise. ${ }^{57}$ If patients with early RA achieved incremental or sustained efficacy with new agents, that could make them more cost effective. However, the need for longer term treatment or longer term implications of toxicity could make them less cost effective. As the use of TNF inhibitors extends to other systemic inflammatory diseases, such as psoriatic arthritis and ankylosing spondylitis, additional specific pharmacoeconomic assessments will need to be performed. ${ }^{59}{ }^{60}$ Of note, these conditions typically affect a younger population, many of whom are in their prime working years. In the case of psoriatic arthritis, the impact of skin involvement on productivity and quality of life also needs to be factored into any pharmacoeconomic assessment.

Additional factors may impact on the health economic implications for TNF inhibitors. For example, as more agents are brought to the clinic, will market forces cause their price to decline? This has certainly been the case with other classes of medication, such as proton pump inhibitors, where competition has resulted in drastically lowered prices. Similarly, will there ever be cheaper generic versions of biological agents $?^{61}$ The situation regarding generic versions is more complex for biologicals than it is for small easily synthesised chemicals. Factors such as variable glycosylation have been shown to affect both the efficacy and toxicity of biological agents; these considerations will certainly impact regulatory approval and, ultimately, cost.

Given the current healthcare environment, pharmacoeconomic considerations are likely to remain a central factor affecting the use of novel therapies in rheumatology and in other disciplines. Understanding these issues will help clinicians choose the optimal therapies for their patients with arthritis.

Competing interests: none declared

Correspondence to: Dr A Kavanaugh, Center for Innovative Therapy and Division of Rheumatology, Allergy, and Immunology, University of California at San Diego, 9500 Gilman Drive, La Jolla, CA USA 920930943; akavanaugh@ucsd.edu

\section{REFERENCES}

1 Pincus T, Kavanaugh A, Sokka T. Benefit/risk of therapies for rheumatoid arthritis: underestimation of the "side effects" or risks of RA leads to underestimation of the benefit/risk of therapies. Clin Exp Rheum 2004;22(suppl 35):S2-S11.

2 Weinblatt ME, Kremer JM, Bankhurst AD, Bulpitt KJ, Fleischmann RM, Fox RI, et al. A trial of etanercept, a recombinant tumor necrosis factor receptor: $\mathrm{Fc}$ fusion protein, in patients with rheumatoid arthritis receiving methotrexate. N Engl J Med 1999;340:253-9.

3 Maini R, St Clair EW, Breedveld F, Furst D, Kalden J, Weisman M, et al. Infliximab (chimeric anti-tumour necrosis factor alpha monoclonal antibody) versus placebo in rheumatoid arthritis patients receiving concomitant methotrexate: a randomised phase III trial. ATTRACT Study Group. Lancet 1999;354:1932-9.

4 Lipsky PE, van der Heijde DM, St Clair EW, Furst DE, Breedveld FC, Kalden JR, et al; Anti-Tumor Necrosis Factor Trial in Rheumatoid Arthritis with Concomitant Therapy Study Group. Infliximab and methotrexate in the treatment of rheumatoid arthritis. N Engl J Med 2000;343:1594-602.

5 Genovese MC, Bathon JM, Martin RW, Fleischmann RM, Tesser JR, Schiff MH, et al. Etanercept versus methotrexate in patients with early rheumatoid arthritis: two-year radiographic and clinical outcomes. Arthritis Rheum 2002;46: 1443-50.

6 van de Putte LB, Rau R, Breedveld FC, Kalden JR, Malaise MG, van Riel PL, et al. Efficacy and safety of the fully human anti-tumour necrosis factor alpha monoclonal antibody adalimumab (D2E7) in DMARD refractory patients with rheumatoid arthritis: a 12 week, phase II study. Ann Rheum Dis 2003;62: 1168-77.

7 Weinblatt ME, Keystone EC, Furst DE, Moreland LW, Weisman MH Birbara CA, et al. Adalimumab, a fully human anti-tumor necrosis factor alpha monoclonal antibody, for the treatment of rheumatoid arthritis in patients taking concomitant methotrexate: the ARMADA trial. Arthritis Rheum 2003;48:35-45.
8 Maini RN, Breedveld FC, Kalden JR, Smolen JS, Furst D, Weisman MH, et al; Anti-Tumor Necrosis Factor Trial in Rheumatoid Arthritis with Concomitant Therapy Study Group. Sustained improvement over two years in physical function, structural damage, and signs and symptoms among patients with rheumatoid arthritis treated with infliximab and methotrexate. Arthritis Rheum 2004; 50: 1051-65.

9 Klareskog L, van der Heijde D, de Jager JP, Gough A, Kalden J, Malaise M, et al; TEMPO (Trial of Etanercept and Methotrexate with Radiographic Patient Outcomes) study investigators. Therapeutic effect of the combination of etanercept and methotrexate compared with each treatment alone in patients with rheumatoid arthritis: double-blind randomised controlled trial. Lancet 2004;363:675-81.

10 Keystone E, Kavanaugh A, Sharp J, Tennenbaum H, Hua Y, Teoh L, et al. Radiographic, clinical, and functional outcomes with adalimumab (a human anti-TNF alpha monoclonal antibody) in the treatment of patients with active rheumatoid arthritis on concomitant methorexate theapy: a randomized, controlled, 52 week-trial. Arthritis Rheum 2004;50:1400-11.

11 Kavanaugh A, Cohen S, Cush J. The evolving use of TNF inhibitors in rheumatoid arthritis. J Rheumatol 2004;31:1881-4.

12 Wong J. Cost-effectiveness of anti-tumor necrosis factor agents. Clin Exp Rheumatol 2005;22(suppl. 35):S65-S70.

13 Lambert CM. Medical therapy for rheumatoid arthritis-value for money? Rheumatology 2001;40:961-4.

14 Hurst NP, Forbes J. Does economic evaluation have anything to offer the rheumatologist? Rheumatology 1999;38:2-5.

15 Ruff B. OMERACT: Economic evaluations and health policy. J Rheumatol 1999;26:2076-7.

16 Gabriel S, Tugwell P, O'Brien B, Yelin E, Drummond M, Ruff B, et al. Report of the OMERACT Task Force on Economic Evaluation. Outcome Measures in Rheumatology. J Rheumatol 1999;26:203-6.

17 Solomon D, Maetzel A. Pharmacoeconomics of prescribing for rheumatoid arthritis. Int J Adv Rheumatol 2004;2:91-6.

18 Weisman M, Gano A, Gabriel S, Hochberg MC, Kavanaugh A, Ofman JJ, et al; Evidence-Based Medicine Working Groups in Rheumatology. Reading and interpreting economic evaluations in rheumatoid arthritis: an assessment of selected instruments for critical appraisal. J Rheumatol 2003;30:1739-47.

19 Wolfe F, Michaud K, Pincus T. Do rheumatology cost-effectiveness analyses make sense? Rheumatol 2004;43:4-6.

20 Maetzel A. Cost-effectiveness analysis: out of touch with clinical reality? Arthritis Rheum (Arthritis Care Res) 2005;53:3-4.

21 Verstappen SMM, Boonen A, Verkleij H, Biilsma JWJ, Buskens E, Jacobs JWG Productivity costs among patients with rheumatoid arthritis: The influence of methods and sources to value loss of productivity. Ann Rheum Dis 2005 (published online-first 5 May 2005 doi 10.1136/ard.2004.033977).

22 Rat A-C, Boissier M-C. Rheumatoid arthritis: direct and indirect costs. Joint Bone Spine 2004;71:518-24.

23 Pisu M, James N, Sampsel S, Saag K. The cost of glucocorticoid-associated adverse events in rheumatoid arthritis. Rheumatology 2005 (in press).

24 Gabriel SE, Crowson CS, O'Fallon WM. Mortality in rheumatoid arthritis: have we made an impact in 4 decades? J Rheumatol 1999;26:2529-33.

25 Pincus T, Sokka T, Wolfe F. Premature mortality in patients with rheumatoid arthritis: evolving concepts. Arthritis Rheum 2001;44:1234-6.

26 Gabriel SE, Crowson CS, Kremers HM, et al. Survival in rheumatoid arthritis: a population-based analysis of trends over 40 years. Arthritis Rheum 2003:48:54-8

27 Pincus T, Brooks RH, Callahan LF. Prediction of long-term mortality in patients with rheumatoid arthritis according to simple questionnaire and joint count measures. Ann Intern Med 1994; 120:26-34.

28 Jantti J, Aho K, Kaarela K, Kautiainen H. Work disability in an inception cohort of patients with seropositive rheumatoid arthritis: a 20 year study. Rheumatology 1999;38:1138-41.

29 Fex E, Larsson BM, Nived K, Eberhardt K. Effect of rheumatoid arthritis on work status and social and leisure time activities in patients followed 8 years from onset. J Rheumatol 1998;25:44-50.

30 Zink A, Braun J, Listing J, Wollenhaupt J. Disability and handicap in rheumatoid arthritis and ankylosing spondylitis-results from the German Rheumatological Database. J Rheumatol 2000;27:613-22.

31 Sokka T, Krishnan E, Hakkinen A, Hannonen P. Functional disability in rheumatoid arthritis patients compared with a community population in Finland. Arthritis Rheum 2003;48:59-63.

32 Wiles NJ, Scott DG, Barrett EM, et al. Benchmarking: the five year outcome of rheumatoid arthritis assessed using a pain score, the Health Assessment Questionnaire, and the Short Form-36 (SF-36) in a community and a clinic based sample. Ann Rheum Dis 2001;60:956-61.

33 Verstappen SMM, Biilsma JWJ, Verkleii H, Buskens E, Blaauw AAM, ter Borg EJ, et al. Overview of work disability in rheumatoid arthritis patients as observed in cross-sectional and longitudinal surveys. Arthritis Rheum (Arthritis Care Res) 2004:51:488-97.

34 Birrell FN, Hassell AB, Jones PW, Dawes PT. How does the short form 36 health questionnaire (SF-36) in rheumatoid arthritis (RA) relate to RA outcome measures and SF-36 population values? A cross-sectional study. Clin Rheumatol 2000; 19:195-9.

35 Wolfe $\mathbf{F}$. The prognosis of rheumatoid arthritis: assessment of disease activity and disease severity in the clinic. Am J Med 1997;103:12S-18S.

36 Gabriel SE, Crowson CS, Campion ME, O'Fallon WM. Indirect and nonmedical costs among people with rheumatoid arthritis and osteoarthritis compared with nonarthritic controls. J Rheumatol 1997;24:43-8.

37 Lajas C, Abasolo L, Bellajdel B, et al. Costs and predictors of costs in rheumatoid arthritis: a prevalence based study. Arthritis Rheum (Arthritis Care Res) 2003;49:64-70. 
38 Dunlop D, Manheim L, Yelin E, Song J, Chang R. The costs of arthritis. Arthritis Rheum (Arthritis Care Res) 2003;49:101-13.

39 Maetzel A, Li LC, Tomlinson G, Bombardier C. The economic burden associated with osteoarthritis, rheumatoid arthritis, and hypertension: a comparative study. Ann Rheum Dis 2004;63:395-401.

40 Cooper NJ. Economic burden of rheumatoid arthritis: a systematic review. Rheumatology 2000;39:28-33.

41 Yelin E, Wanke LA. An assessment of the annual and long-term direct costs of rheumatoid arthritis: the impact of poor function and functional decline. Arthritis Rheum 1999;42:1209-18.

42 Fries JF. Safety, cost and effectiveness issues with disease modifying antirheumatic drugs in rheumatoid arthritis. Ann Rheum Dis 1999;58(suppl I):186-189.

43 Kobelt G, Eberhardt K, Jonsson L, Jonsson B. Economic consequences of the progression of rheumatoid arthritis in Sweden. Arthritis Rheum 1999:42:347-56

44 Kobelt G, Jonsson L, Lindgren P, Young A, Eberhardt K. Modeling the progression of rheumatoid arthritis: a two-country model to estimate costs and consequences of rheumatoid arthritis. Arthritis Rheum 2002;46:2310-19.

45 Michaud K, Messer J, Choi H, Wolfe F. Direct medical costs and their predictors in patients with rheumatoid arthritis: a three-year study of 7,527 patients. Arthritis Rheum 2003;48:2750-62.

46 Guillemin F. The value of utility: assumptions underlying preferences and quality adjusted life years. J Rheumatol 1999:26:1861-3.

47 Wong JB, Singh G, Kavanaugh A. Estimating the cost-effectiveness of 54 weeks of infliximab for rheumatoid arthritis. Am J Med 2002;113:400-8.

48 Kobelt G, Jonsson L, Young A, Eberhardt K. The cost-effectiveness of infliximab (Remicade) in the treatment of rheumatoid arthritis in Sweden and the United Kingdom based on the ATTRACT study. Rheumatology 2003;42:326-35.

49 Kobelt G, Eberhardt K, Geborek P. TNF inhibitors in the treatment of rheumatoid arthritis in clinical practice: costs and outcomes in a follow up study of patients with RA treated with etanercept or infliximab in southern Sweden. Ann Rheum Dis 2004;63:4-10.
50 Brennan A, Bansback N, Reynolds A, Conway P. Modelling the costeffectiveness of etanercept in adults with rheumatoid arthritis in the UK. Rheumatology 2004;43:62-72.

51 Kavanaugh A, Han C, Bala M. Functional status and radiographic joint damage are associated with health economic outcomes in patients with rheumatoid arthritis. J Rheumatol 2004;31:849-55.

52 Yelin E, Trupin L, Katz P, Lubeck D, Rush S, Wanke L. Association between etanercept use and employment outcomes among patients with rheumatoid arthritis. Arthritis Rheum 2003:48:3046-54.

53 Bansback NJ, Brennan A, Sengupta N, Pang F. The cost effectiveness of adalimumab (HUMIRA) in UK patients with moderate to severe RA [abstract] Ann Rheum Dis 2004;63(suppl 1):512-13.

54 Bansback NJ, Brennan A, Sengupta N. The cost effectiveness of adalimumab (HUMIRA) in patients with RA: a Finnish analysis [abstract]. Ann Rheum Dis 2004;63(suppl 1):513-14.

55 Choi HK, Seeger JD, Kuntz KM. A cost-effectiveness analysis of treatment options for patients with methotrexate-resistant rheumatoid arthritis. Arthritis Rheum 2000:43:2316-27.

56 Kavanaugh A, Heudebert G, Cush J, Jain R. Cost evaluation of novel therapeutics in rheumatoid arthritis (CENTRA): a decision analysis model. Semin Arthritis Rheum 1996;25:297-307.

57 Hallert E, Husberg $M$, Jonsson D, Skogh T. Rheumatoid arthritis is already expensive during the first year of disease. Rheumatol 2004;43:1374-82.

58 Quinn $\mathrm{M}$, Conaghan $\mathrm{P}, \mathrm{O}^{\prime}$ Connor $\mathrm{P}$, et al. Very early treatment with infliximab in addition to methotrexate in early, poor-prognosis rheumatoid arthritis reduces magnetic resonance imaging evidence of synovitis and damage, with sustained benefit after infliximab withdrawal. Arthritis Rheum 2005:52:27-35.

59 Kavanaugh A, Krueger G, Yan S, Bala M, Zhou B, Dooley L, et al. Effect of infliximab therapy on employment, time lost from work, and productivity in patients with psoriatic arthritis. Arthritis Rheum 2004;50(suppl):S318.

60 Kobelt G, Sandlin-Sobocki P, Brophy S, Jonsson L, Calin A, Braun J. The burden of ankylosing spondylitis and the cost-effectiveness of treament with infliximab. Rheumatology 2004;43:1 158-66.

61 Jonietz E. Generic biotech. Technol Rev 2004;107:54-8. 